\title{
The Deep Sea Frontier: A New European Research Initiative
}

\author{
by Amelie Winkler, Jürgen Mienert, Catherine Mevel, and Sören Dürr
}

\section{Introduction}

The deep sea and the deep marine seafloor form an extensive and complex bio-geosphere system. It modulates global climate and global ocean circulation, contains many of today's and tomorrow's marine resources, and hosts a partly unknown, but significant part of earth's biosphere. The Deep Sea Frontier Initiative is a new European research initiative in which the three research communities of ocean drilling, ocean margin research, and seafloor observatories will combine forces to substantially advance our knowledge base in areas such as (geo)hazards, global climate change and the sustainable exploitation of biological and geological resources of the deep sea and its floor.

Scientific drilling into the ocean floor is fundamental to the study of deep sea floor processes, because it provides the only access to deep and direct sampling and in situ monitoring of the ocean subsurface. Drilling projects, however, should be prepared with a multi-disciplinary and multi-tool approach. The European Consortium for Ocean Research Drilling (ECORD) therefore approached other research programs in Europe involved in paleoclimate studies (IMAGES), ocean margin research (EUROMARGINS, HERMES) and seafloor observation (ESONET) to develop a joint European program on deep-sea science. ECORD is supported by the European Commission through an ERANet, the ECORDNet, of which one specific goal is to establish and strengthen co-operation with other programs and research communities.

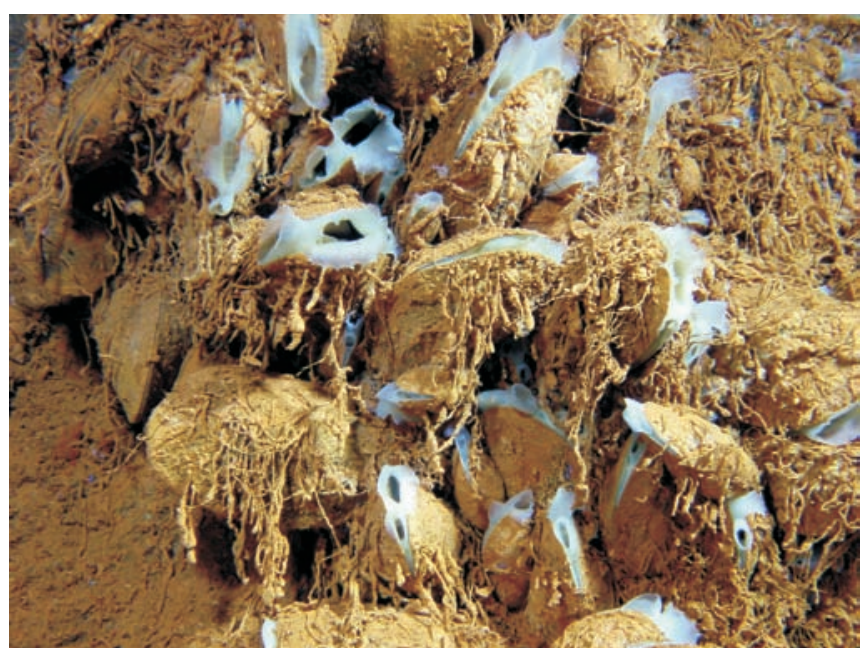

Bathymodiolus azoricus mussels at the Rainbow hydrothermal field, MidAtlantic ridge. Copyright ATOS/IFREMER
A workshop was held in Naples, Italy, 1-2 June 2006, to identify research needs and new research targets in European marine sciences. Invitations were issued to scientists from Europe and Canada, and to representatives from the petroleum industry, as well as the European funding agencies. Splitting up into separate working groups a total of seventy participants discussed the six main topics related to the investigation of the deep sea:

\section{Topics}

- History, monitoring and prediction of geohazards

Seismic activity represents a major hazard for parts of southern Europe. Low stability of volcano flanks along the Mid-Atlantic ridge and continental margin slope instability is a hazard for coastal communities if associated with tsunami generation. Submarine slides can as well be a threat to seabed installations. The goal of this research is a better understanding of processes leading to hazardous events, mapping of risk sites in European waters, modeling geohazards, and conduct a risk assessment for European waters.

- Geosphere-biosphere interactions affecting margins, oceans and the atmosphere

Greenhouse gases such as methane and carbon dioxide form or escape naturally from the seabed and may have a substantial influence on the biosphere and on atmospheric changes. Much of these gases are bound by bacterial communities inside the deep sea floor. However, it remains unclear how much greenhouse gas eventually enters the atmosphere. Quantification of the respective processes in the seafloor and in the water column and the role of the ocean in the carbon cycle is therefore of high priority in research.

- Long-term climatic control and feed-backs in the deep-sea environment

The Earth's climate system responds to the rising concentration of greenhouse gases in the atmosphere in a complex and poorly understood way. The deep-sea floor provides the largest continuous archive and reference frame for predicting future climate change by allowing an investigation of Earth's climate system dynamics in the past at decadal to millionyear timescales.

- Evolution of deep-sea ecosystems: functioning, diversity and conservation 
The biota of the deep sea floor remains largely unexplored. Only a small fraction has been sampled spatially, and even fewer areas have been sampled temporally. Industrial fisheries worldwide progressively target their activities into the deep oceans. In addition, new types of chemosynthetic ecosystems that feed on fluid vents on the seafloor have been formed on continental margins and at mid-ocean ridges. Integrated investigations of how they are distributed and how they link with the geological processes controlling fluid venting will throw light on their sensitivity to direct and indirect human impact and global change.

- The deep sea landscape: sediment transport and fluxes

The seafloor landscape (or seascape) is modified by a variety of processes active during timespans from literally instantaneous to millions of years. Climate-driven sea level oscillations, oceanic currents, tectonic settings, fluid- and sediment flow all contribute to the shaping of the deep sea floor. In addition, human activity significantly affects sediment transport and particle flux. Prospective research in this field should be multi-disciplinary, covering wide temporal and spatial ranges and apply new improved and efficient technologies for high resolution in situ data gathering within the water column, the seafloor and the subseafloor.

- Sustainable exploitation of deep sea resources

Established fisheries and hydrocarbon extraction are moving rapidly and steadily downslope as shallower and better accessible resources become depleted. The current and anticipated economic activity in Europe's deep water however, will lead to user conflicts. To properly address these issues and establish functional management strategies, data from different sources must be integrated, including oceanographic, geophysical, geological, hydrological, biological, social and economical data.

\section{Road Map Investigating the Deep Seafloor}

The workshop participants recognized that a concerted and multi-scale approach involving forefront research groups from different laboratories and disciplines and the best technologies and research platforms available, is key to success in this research initiative. High resolution geophysical and geological mapping and imaging of the seabed and associated biomass, laboratories at the seafloor and in the water column, drilling the subsurface, deploying observatories on the seabed and in boreholes to monitor long-term variations, will all be essential activities that need coordination at all levels.

In order to meet these new challenges, the infrastructure and capability of European marine geoscience and technology on the deep sea floor is to be significantly improved. Key areas will include technologies to sample the deep subseafloor biosphere by drilling with the Integrated Ocean Drilling Program (IODP), the capability within the academic geoscience community to collect 3-D seismic reflection data,

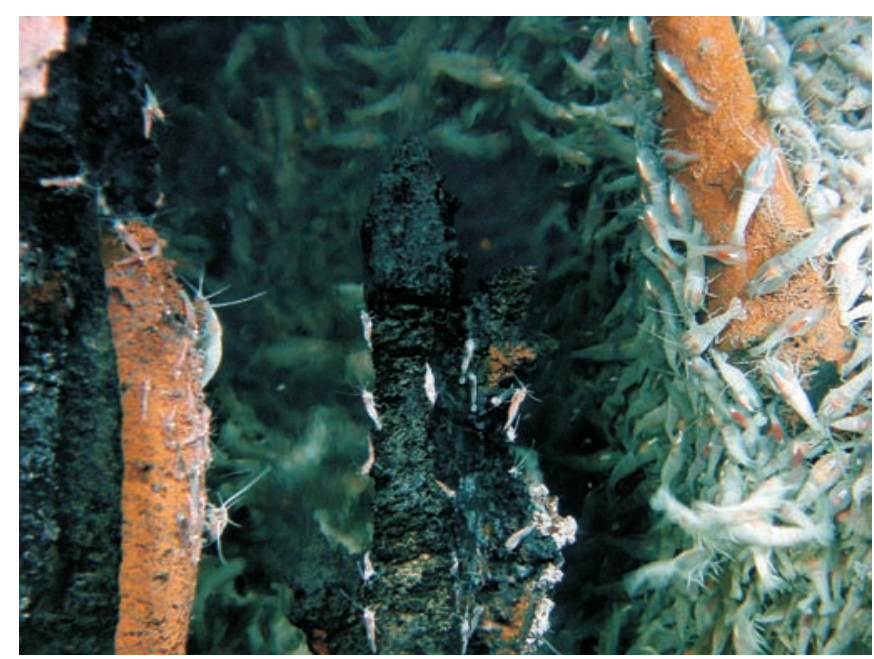

Rimicaris exoculata shrimps on hydrothermal chimneys at the Rainbow field, Mid-Atlantic ridge. Copyright ATOS/IFREMER

a research strategy to address the marine methane cycle, the mapping of geohazards and risk mitigation, prediction of climate change and its impact on ecology and society, and the sustainable exploitation of deep sea resources.

The Deep Sea Frontier initiative is rooted as a multinational activity building up environmental research in context of the Framework Programs (FP7 and beyond) of the European Commission. Based on the outcome of the workshop a "Foresight Paper" on strategies for deep sea research in the next decade is planned to be published in mid 2007 (see Web Link below).

\section{Contact}

Sören Dürr, Deutsche Forschungsgemeinschaft, Germany; email: soeren.duerr@dfg.de. http://www.ecord. org/enet/deepsea-frontier.html

\section{Authors}

Amelie Winkler, Program Officer, Deutsche Forschungsgemeinschaft (DFG), Kennedyallee 40, 53175 Bonn, Germany, e-mail: Amelie.Winkler@dfg.de

Catherine Mevel, ECORD Managing Agency, IPGP, 4 place Jussieu, 75252 Paris cedex 05, France.

Jürgen Mienert, Professor, University of Tromsø, Dramsveien 201, N-9037 Tromsø, Norway.

Sören Dürr, Program Director, Deutsche Forschungsgemeinschaft (DFG), Kennedyallee 40, 53175 Bonn.

\section{Related Web Link}

http://www.ecord.org/enet/deepsea-frontier.html 